\title{
A Study to Evaluate the Effectiveness of Structured Teaching Program in Lifestyle Change Knowledge and Practice of Preventing Hypertension in Middle-aged Adults
}

\author{
Pooja Devi $^{1}$, Promila Pandey ${ }^{2}$ \\ ${ }^{1}$ Department of Medical Surgical Nursing, Maharaja Agrasen Medical College of Nursing, Agroha, Hisar Haryana, India \\ ${ }^{2}$ Principal, Department of Medical Surgical Nursing, Maharaja Agrasen Medical College of Nursing, Agroha, Hisar Haryana, India \\ bishlaypooja@gmail.com
}

\begin{abstract}
A pre experimental study to assess the effectiveness of structured teaching programme on knowledge and practice regarding life style modification to prevent hypertension among middle age adults in selected rural area at district Hisar (Haryana) was conducted with the objectives to assess the pre - test knowledge score and practices score regarding life style modification to prevent hypertension among middle age adults and to evaluate the structured teaching programme regarding life style modification to prevent hypertension among middle age adults. The conceptual framework was based on Context, Input, Process and Product (CIPP) Model on evaluation developed by Daniel Stufflebeam (1971). An evaluation research approach and pre - experimental one group pretest posttest research design was adopted for the study. sample size was 60 subjects selected by convenient Sampling technique. Data was collected through checklist \& structured interview knowledge questionnaire to assess the knowledge and practice regarding life style modification to prevent hypertension among middle age adults. Major finding of the study were the most common found depicts the comparison of the mean knowledge scores between the pre and posttest on knowledge regarding life style modification to prevent hypertension. The area wise distribution of the knowledge score of middle age adults reveals that the posttest means with $S D(24.2 \pm 2.552)$ was higher than pretest mean with $S D(15.98 \pm 3.610)$ with the mean difference of 8.233 . ' $t$ ' value was computed to find the level of significance between the mean and it was observed highly significant $(' t$ ' $=28.730)$ at $p<0.05$ level. the area wise distribution of practice score overall posttest mean with $S D(12.45 \pm 1.556)$ was higher than pretest mean with $S D(4.58 \pm 1.700)$ with the mean difference of 7.867 . ' $t$ ' value was computed to find the level of significance between the mean and it was observed highly significant (' $t$ ' $=25.499)$ at $p<0.05$. the study also show the area wise effectiveness of structured teaching programme on pre knowledge level and post level knowledge score. same as area wise effectiveness of practice score pre and post practice. The result of study shows that a structured teaching programme help in increase the knowledge and improve the practice regarding life style modification to prevent hypertension among middle age adults. Recommendations were that a similar study can be conducted on large scale from various areas and experimental study can be conducted with a control group.
\end{abstract}

Keywords: Life style modification, hypertension, middle age adults

\section{Introduction}

"We cannot change our genes or sex, but we can definitely modify our life style thereby protecting our self from Hypertension"

\section{Robert C Schlant}

Hypertension is one of the most common health problems in the world. Hypertension is called the "silent killer" because people are symptoms free. Although hypertension can be modified, it is a leading risk factor for mortality and there is a large proportion of elderly patients whose blood pressure remains uncontrolled. Knowledge and life style modifications of patients play an important role in the controlling of hypertension and preventing their long - term complications. Hypertension is a major worldwide public health problem because of its high prevalence with vascular disease, premature death, stroke, renal diseases and retinopathy. [1]

Hypertension is a leading cause of cardiovascular disease. There are very few studies dealing with the incidence of hypertension and changes in blood pressure over time. We aimed to evaluate the prevalence and incidence of hypertension within a population. According to World Health Report 2002, cardiovascular diseases will be the largest cause of death and disability by 2020 in India. In 2020 AD, 2.6 million Indians are predicted to die due to coronary heart disease which constitutes $54.1 \%$ of all cardiovascular disease deaths. Nearly half of these deaths are likely to occur in young and middle - aged individuals (30 - 69 years). Currently Indians experience cardiovascular disease deaths at least a decade earlier than their counterparts in countries with established market economies (EME). [2]

Some types of hypertension can be managed through lifestyle and home remedies s, such as engaging in physical activity, reducing alcohol and tobacco use, and avoiding a high - sodium diet, reducing the amount of salt: Average salt intake is between 9 grams $(\mathrm{g})$ and $12 \mathrm{~g}$ per day in most countries around the world. The WHO (world health organization) recommends reducing intake to under $5 \mathrm{~g}$ a day, to help decrease the risk of hypertension and related health problems. This can benefit people both with and without hypertension, but those with high blood pressure will benefit the most, Moderating alcohol consumption: 
Moderate to excessive alcohol consumption is linked to raised blood pressure and an increased risk of stroke. [3]

Among rural areas, eastern India had the highest prevalence equaling the prevalence seen in urban parts of India. The prevalence of hypertension in urban parts of India was similar across all the four regions. Considerable variation in prevalence of hypertension, (20-59\%) was seen among the studies from rural east India with higher prevalence seen from Assam (owing to the indigenous prevalence of excess salt, alcohol, and Khaini consumption among tea plantation workers of Assam). A higher prevalence was also noted in Car Nicobar Islands as compared with other rural southern regions. One - third of urban Indians from all the four regions of India were hypertensive. [4]

Lifestyle behavior modifications are the first line of intervention for all patients with hypertension, in combination with pharmacological treatment which is also important for the disease management to control its progress and prevent short and long term complications. Therefore, lifestyle modifications should be actively performed not only before but also after starting of antihypertensive medications to improve patients controlling outcomes. [5]

Lifestyle modifications are including; weight control, limitation of alcohol consumption, increased physical activity, increased fruit and vegetable consumption, reduced total fat and saturated fat intake, and smoking cessation. Dietary approach to control hypertension, (DASH) eating plan which are effectively lower hypertension should be encouraged for these patients. It emphasizes fruits, vegetables, and low - fat dairy products and reduces in fat and cholesterol, other dietary factors, such as a greater intake of protein or monounsaturated fatty acids, may also reduce blood pressure. [6]

A healthy lifestyle decreases blood pressure, enhances antihypertensive drug efficacy and decreases total cardiovascular risk. Their strategy for a healthy lifestyle is supported and includes the following elements: Achieve and maintain ideal weight with a body mass index between 18.5 and $24.9 \mathrm{~kg} / \mathrm{m} 2$ by means of limiting caloric intake and increasing daily physical activity. [7]

Fadwa ALHALAIQA (2017) conducted a descriptive study of adherence to lifestyle modification factors among hypertensive patients. . the result revealed that our participant did not follow the healthy life style modification. for example, the mean blood sugar (BS) level, body mass index (BMI), and cholesterol levels were $155 \mathrm{mg} / \mathrm{dL}$ (standard deviation $(\mathrm{SD})=71.9), 29 \mathrm{~kg} / \mathrm{m} 2(\mathrm{SD}=5.4)$, and $197 \mathrm{mg} / \mathrm{dL}(\mathrm{SD}=86.6)$, respectively. A significant correlation was shown between age and BP $(\mathrm{P}=0.000)$. Increase in diastolic BP (DBP) correlated with a significant increase in cholesterol level $(\mathrm{P}=0.002)$ and $\mathrm{BMI}(\mathrm{P}=$ 0.006). [8]

\subsection{Objective}

- To assess the pre - test knowledge score and practices score regarding life style modification to prevent hypertension among middle age adults.
- To administer structured teaching programme regarding life style modification to prevent hypertension among middle age adults.

- To assess the posttest knowledge score and practices score regarding life style modification to prevent hypertension among middle age adults.

- To find out the association between the pretest knowledge score and practices score regarding life style modification to prevent hypertension among middle age adults with selected demographic variables

\subsection{Hypothesis}

- $\mathbf{H}_{1:}$ The mean post knowledge score and practice score regarding life style modification to prevent hypertension among middle age adults who have undergone the structured teaching programme will be significant higher than the mean pretest knowledge score and practice score at 0.05 level of significance.

- $\mathbf{H}_{2:}$ There will be significant association between the pretest knowledge score and pretest practice score regarding life style modification to prevent hypertension among middle age adults with selected demographic variable at 0.05 level of significance.

\section{Material Method}

A pre experimental study to assess the effectiveness of structured teaching programme on knowledge and practice regarding life style modification to prevent hypertension among middle age adults in selected rural area at district Hisar (Haryana)."

The Conceptual framework selected for this study was based on CIPP (Context, Input, Process and Product) developed by Daniel Stuffle Beam (1983). The research approach used in this study is Evaluatory research approach. The tool was tried on 6 peoples in Agroha (Hisar). The reliability of the tool was established by using Test and Re - test method for knowledge.

Data collection to assess the availability of sample and feasibility of the study of tobacco consumption hazards among middle aged population in Agroha, Hisar. Prior permission was obtained from the ethical committee of institution through Principal, MACON Agroha. Ethical approval was obtained from Sarpanch of village Meerpur, Hisar. Written informed consent from adults of Meerpur was obtained for the willingness to participate themselves and their infants in the study. Study was conducted in the month of March 2019. The data analysis through descriptive and inferential statistics data to determine the knowledge regarding tobacco consumption hazards among middle aged population.

\section{Results}

Section A - Description of demographic variables of the sample. 
Table 1: Frequency and percentage distribution of sample characteristic

\begin{tabular}{|c|c|c|c|}
\hline \multicolumn{2}{|c|}{$\begin{array}{c}\text { SECTION - } 1 \text { Socio - demographic } \\
\text { Performa }\end{array}$} & $\begin{array}{c}\text { Percentage } \\
(\%)\end{array}$ & $\begin{array}{l}\text { Frequency } \\
\text { (f) }\end{array}$ \\
\hline \multirow{4}{*}{ Age } & $30-35$ years & $23.30 \%$ & 14 \\
\hline & $36-40$ Years & $18.30 \%$ & 11 \\
\hline & $41-45$ years & $25.00 \%$ & 15 \\
\hline & $46-50$ years & $33.30 \%$ & 20 \\
\hline \multirow{2}{*}{ Gender } & Male & $91.70 \%$ & 55 \\
\hline & Female & $8.30 \%$ & 5 \\
\hline \multirow{4}{*}{ Education } & Primary Education & $26.70 \%$ & 16 \\
\hline & Secondary Education & $33.30 \%$ & 20 \\
\hline & Graduate/post Graduate & $18.30 \%$ & 11 \\
\hline & Illiterate & $21.70 \%$ & 13 \\
\hline \multirow{3}{*}{ Occupation } & Sedentary Worker & $16.70 \%$ & 10 \\
\hline & Moderate Worker & $76.70 \%$ & 46 \\
\hline & Heavy Worker & $6.70 \%$ & 4 \\
\hline \multirow{4}{*}{ Religion } & Hindu & $98.30 \%$ & 59 \\
\hline & Muslim & $1.70 \%$ & 1 \\
\hline & Christian & $0.00 \%$ & 0 \\
\hline & Others & $0.00 \%$ & 0 \\
\hline \multirow{2}{*}{$\begin{array}{l}\text { Dietary } \\
\text { Pattern }\end{array}$} & Vegetarian & $58.30 \%$ & 35 \\
\hline & Non vegetarian & $41.70 \%$ & 25 \\
\hline \multirow{4}{*}{$\begin{array}{l}\text { Source Of } \\
\text { Information }\end{array}$} & Mass Media & $16.70 \%$ & 10 \\
\hline & Health Professionals & $66.70 \%$ & 40 \\
\hline & Family & $16.70 \%$ & 10 \\
\hline & Others & $0.00 \%$ & 0 \\
\hline
\end{tabular}

Table - 1: shows the majority (33.3\%) of the Sample were in the age group of 46 - 50years. $25.0 \%$ in age group of 41 45 years. $23.3 \%$ in the age group of $30-35$ year. $18.3 \%$ in the age group 36 - 40 years.

$18.3 \%$ in the age group $36-40$ years.

Section B- Assessment the pre - test knowledge score and practice score regarding life style modification to prevent hypertension among middle age adults

\section{Part- I: Criteria Measure of pre - test knowledge score}

Pre Knowledge score

Table 2

$\mathbf{N}=60$

\begin{tabular}{|c|c|c|c|}
\hline \multirow{2}{*}{$\begin{array}{c}\text { Level of } \\
\text { knowledge }\end{array}$} & \multirow{2}{*}{ Range of scores } & \multicolumn{2}{|c|}{ Pretest } \\
\cline { 3 - 4 } & & Frequency & Percentages \\
\hline Inadequate & $0-10$ Scores & 6 & $10 \%$ \\
\hline Moderate & $11-20$ Scores & 51 & $85 \%$ \\
\hline Adequate & $21-30$ Scores & 3 & $5 \%$ \\
\hline
\end{tabular}

Maximum=30 Minimum=0

Table - 2 Shows the criterial measure of knowledge score it consist of 30 items on the level of knowledge of middle aged adults regarding life style modification to prevent hypertension. Each question has one correct response and three incorrect responses with score zero. Maximum score will be 30. to Interpret level of knowledge the score will be distributed as subject have 0 - 10 marks have inadequate knowledge, 11 - 20 marks out of 30 have moderate knowledge and 21 - 30 marks out of 30 have adequate knowledge.

Table 3: Criteria Measure of pre practice score, $N=60$

\begin{tabular}{|c|c|c|c|}
\hline \multirow{2}{*}{$\begin{array}{c}\text { Level of } \\
\text { practice }\end{array}$} & \multirow{2}{*}{ Range of scores } & \multicolumn{2}{|c|}{ Pretest } \\
\cline { 3 - 4 } & & Frequency & Percentages \\
\hline Poor & $0-5$ Scores & 51 & $85 \%$ \\
\hline Average & $6-10$ Scores & 7 & $11.70 \%$ \\
\hline Good & $11-16$ Scores & 2 & $3.30 \%$ \\
\hline
\end{tabular}

Maximum=16 Minimum $=0$

Table- 3 It depict the overall criteria of pre - practice score regarding life style modification to prevent hypertension among middle age adults. the result shows that 51 (85\%) had poor practice, $7(11.7 \%)$ had the average practice and only 2 (3.3\%) had good practice of middle age adults.

Table 4: Overall effectiveness of structured teaching programme on practice, $\mathrm{N}=60$

\begin{tabular}{|c|c|c|c|c|c|c|c|c|c|}
\hline \multicolumn{2}{|c|}{ Paired T, test } & mean & SD & Mean\% & Mean difference & Paired T Test & P value & Table value at 0.05 & Result \\
\hline \multirow{2}{*}{ Practice } & Pre - Test & 4.58 & 1.700 & 28.65 & \multirow{2}{*}{7.867} & 25.499 & 0.0000 & \multirow{2}{*}{2.00} & Significant \\
\cline { 2 - 9 } & Post - Test & 12.45 & 1.556 & 77.81 & & & & & \\
\hline
\end{tabular}

Maximum $=16$

Minimum $=0$

Table no - 4 depicts the comparison of the mean practice scores between the pre and posttest regarding life style modification to prevent hypertension. The area wise distribution of the knowledge score of middle age adults reveals that the posttest means with $\mathrm{SD}(12.45 \pm 1.556)$ was higher than pretest mean with SD $(4.58 \pm 1.700)$ with the mean difference of 7.867. ' $t$ ' value was computed to find the level of significance between the mean and it was observed highly significant (' $\mathrm{t}$ ' $=25.499$ ) at $\mathrm{p}<0.05$ level.

Part II: Overall effectiveness of structured teaching programmen on knowledge score

Table 5: Evaluate the effectiveness of structured teaching programme

\begin{tabular}{|c|c|c|c|c|c|c|c|c|c|}
\hline \multicolumn{2}{|c|}{ Paired T, test } & Mean & SD & Mean\% & Mean difference & Paired T Test & P value & Table value & Result \\
\hline \multirow{2}{*}{ Knowledge } & Pre- Test & 15.98 & 3.610 & 53.28 & \multirow{2}{*}{8.233} & \multirow{2}{*}{28.730} & \multirow{2}{*}{0.0000} & \multirow{2}{*}{2.00} & \multirow{2}{*}{ Significant } \\
\hline & Post- Test & 24.22 & 2.552 & 80.72 & & & & & \\
\hline
\end{tabular}

Table- 5 depicts the comparison of the mean knowledge scores between the pre and posttest on knowledge regarding life style modification to prevent hypertension. The area wise distribution of the knowledge score of middle age adults reveals that the posttest mean with SD $(24.22 \pm 3.610)$ was higher than pretest mean with SD $(15.98 \pm 2.552)$ with the mean difference of 8.233 ' $t$ ' value was computed to find 
the level of significance between the mean and it was observed highly significant (' $t$ ' $=28.730)$ at $\mathrm{p}<0.05$ level.

Table 6: Overall effectiveness of structured teaching programmen on practice score, $\mathrm{N}=60$

\begin{tabular}{|c|c|c|c|c|c|c|c|c|c|}
\hline \multicolumn{2}{|c|}{ Paired T, test } & mean & SD & Mean\% & Mean difference & Paired T Test & P value & Table value at 0.05 & Result \\
\hline \multirow{2}{*}{ Practice } & Pre- Test & 4.58 & 1.700 & 28.65 & 7.867 & 25.499 & 0.0000 & 2.00 & Significant \\
\cline { 2 - 5 } & Post- Test & 12.45 & 1.556 & 77.81 & & & & \\
\end{tabular}

\section{Maximum $=16$}

Minimum $=0$

Table no - 6depicts the comparison of the mean practice scores between the pre and posttest regarding life style modification to prevent hypertension. The area wise distribution of the knowledge score of middle age adults reveals that the posttest means with $\mathrm{SD}(12.45 \pm 1.556)$ was higher than pretest mean with SD $(4.58 \pm 1.700)$ with the mean difference of 7.867. ' $t$ ' value was computed to find the level of significance between the mean and it was observed highly significant (' $\mathrm{t}$ ' $=25.499$ ) at $\mathrm{p}<0.05$ level.

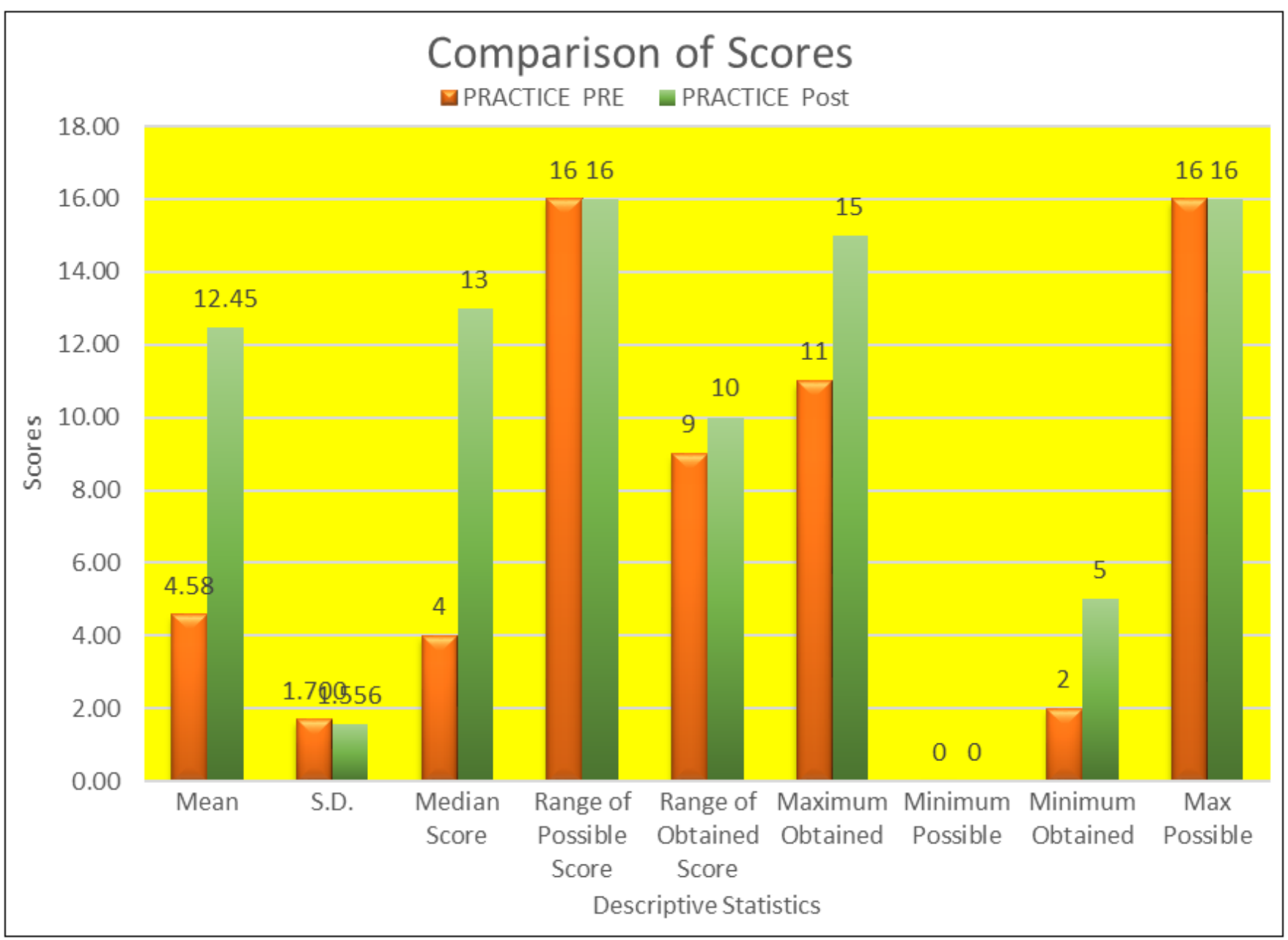

\section{Discussion}

The study was conducted to find out the knowledge and practice regarding life style modification to prevent hypertension among middle age adults. The finding of the study has been discussed with reference to the objectives and hypothesis of the study.

Majority of subject $55(91.7 \%)$ had adequate knowledge score and only $5(8.3 \%)$ had inadequate knowledge regarding life style modification to prevent hypertension among middle age adults. further none of the middle age adults had inadequate knowledge score in the post test. Majority of subject 57 (95\%) had good practice score and only $2(3.3 \%)$ had average practices regarding life style modification to prevent hypertension among middle age adults. further $1(1.7 \%)$ of the middle age adults had poor practice score in the post test.

Puveearasan Kongarasan; (2018), conducted a study to assess the Knowledge and perception of hypertension among hypertensive patients attending rural health and training center, department of community medicine, SRMC \& RI. The mean age of participants is 55.6 \pm 10.06 . More than half of the participants were female $64 \%$. Among them $18 \%$ were illiterate and $37.1 \%$ were unemployed. It was observed that $24 \%$ of participants were diagnosed to have hypertension for less than 1 year, $50 \%$ between 1 - 5 years, $16 \%$ between 5 - 9 years and $10 \%$ more than 10 years. Around $36 \%$ of the participants had family history of 
hypertension. In this study $22 \%$ of the participants were diabetic and $12 \%$ suffered from Bronchial asthma.16\% had habit of smoking, while $18 \%$ had history of alcohol consumption About $94 \%$ had knowledge about the causes of Hypertension, 96\% about the symptoms, accurate method for monitoring $96 \%$, mode of treatment $96 \%, 76 \%$ about the parts mainly affected by hypertension and $90 \%$ had the knowledge about the symptoms of hypertension ${ }^{9}$.

Dhakal M.; (2017), conducted a study which hospital based cross sectional study to evaluate awareness of lifestyle intervention among hypertension patient in Sikkam among all the hypertensive patient examined in the study $(n=100)$, 62 were female and 38 were male. 92 patient were receiving pharmacotherapy and only 32 patient had their blood pressure adequately controlled.20 female and 12 males had BP under control and difference was statically insignificant. $\{\mathrm{p}=0.94$, or 1 . $\mathrm{o} 3$, CI95\% [(90.43 - 2.45) $] .52$ were uneducated or had only basic education out of total $100(62$ female and 38 males) patients. 26 patient out of 60 patient and 26 patients out of 60 patients and 26 patient out of 40 patients had only basic education or were uneducated effect of gender on patient knowledge on life style modification for the management of hypertension was insignificance $[\mathrm{p}=0.74$, OR0.87, 95\%CI [(0.38 - 1.97) ] and for education background it was significant $[\mathrm{p}=0.04$ or $0.41,95 \%$ [CI (0.18 - 0.94) ]. Urban to rural ratio was 54: 6 as opposed to 20: 20 in unaware group. Urban population was more aware as compared to rural population [ $\mathrm{p}=$ less than0001 or 9, 95\% CI (3.12 - 25.63). blood pressure was significant under control in the population having adequate knowledge $[\mathrm{p}=0.04$ or $2.6,95 \%$ CI $[(0.49-2.86)]$. Similarly it was insignificant for smoking consumption or alcohol intake $\left(\mathrm{p}=1\right.$ and 0.142 respectively) ${ }^{10}$.

\section{Conclusion}

The present research study is concluded with implication to nursing field limitation and delimitation with study design and method and recommendation for the knowledge and practice score of middle age adults regarding life style modification to prevent hypertension. this will help the middle age adults to gain knowledge and improve practice in the area of "General Information regarding hypertension, knowledge related to risk factor of Hypertension, knowledge of middle age adults related symptom\& causes of hypertension, general information of life style modification, knowledge related to prevention of hypertension, Knowledge related to management of hypertension, knowledge of middle age adults related to complication of hypertension. This will also help to improve practice areas the enhancement of practice score was more in practice related to diets, practice related to sedentary activities, practice related to physical activities, practice related to treatment.

The study involves on group pretest posttest design with convenient sampling technique to select the sample. The sample size was 60 middle age adults. Sample was selected according to the inclusive and exclusive criteria. Structured interview knowledge questionnaires were used to assess the knowledge level of middle age adults regarding life style modification to prevent hypertension. Checklist was used to assess the practice of middle age adult regarding life style modification to prevent hypertension. Post test was conducted after $7^{\text {th }}$ day with same questionnaires to assess the knowledge and checklist to assess the practice of middle age adults.

The following conclusions are draw on basis of the finding of this study:

Age wise distribution of study sample revealed that the higher percentage $33.3 \%$ of the Sample were in the age group of 46 - 50years. $25.0 \%$ of respondent were in the age group of $41-45$ years, $23.3 \%$ were in the age group of 30 35 years. $18.3 \%$ were in the age group 36 - 40years. with regard of to the gender of the middle age adults, the majority $(91.7 \%)$ of the sample were in the male. $(8.3 \%)$ of the sample were females. Majority of sample $(33.3 \%)$ were secondary education. $26.7 \%$ were primary education, $21.7 \%$ were illiterate only $18.3 \%$ were graduated. In term of occupation, majority of sample $76.7 \%$ were moderate worker, $16.7 \%$ were sedentary worker only $6.7 \%$ were heavy worker In terms of religion, majority of samples (98.3\%) were Hindu, only $1.7 \%$ were Muslim. the regarding dietary pattern, majority of sample $58.3 \%$ were Hindu, 41.7 $\%$ were non - vegetarian. in term of source of information wise distribution, $66.7 \%$ were having knowledge from health professional, $16.7 \%$ were from mass media, 16.7 were having knowledge from family.

- In pretest $51(85 \%)$ of the middle age adults had moderate knowledge, $6(10 \%)$ had inadequate knowledge and $3(5 \%)$ had the adequate knowledge score in pretest.

- In pretest $51(85 \%)$ of the middle age adults had poor practice, 7 (11.7\%) had average practice and $2(3.3 \%)$ had the good practice score in pre - test.

- The enhancement of knowledge score was more in the area of Knowledge related to the "General Information regarding hypertension" (2.217), "knowledge related to risk factor of Hypertension" (.0.550), "knowledge of middle age adults related symptom\& causes of hypertension" (1.400) knowledge related "general information of life style modification", (0.550) "knowledge related to prevention of hypertension" (1.317) "Knowledge related to management of hypertension" (1.700), "knowledge of middle age adults related to complication of hypertension" (1.000).

- The enhancement of practice score was more in "practice related to diets" (2.133), " practice related to sedentary activities" (0.717) "practice related to physical activities " (1.400), "practice related to treatment" (3.617).

- The mean post -test knowledge score 24.22 was higher than pre knowledge score 15.98 suggested that structured teaching programme helped in improving the knowledge of middle age adults regarding life style modification to prevent hypertension.

- The mean post -test practice score 12.45 was higher than pre practice score 4.58 suggested that structured teaching programme helped in improving the practices.

- The mean difference between the posttest knowledge score and pretest knowledge score of middle age adults was found higher significant 8.233 with paired ' $t$ ' test $(\mathrm{t}=28.730)$

- The mean difference between the posttest practice score and pretest practices score of middle age adults was 
found higher significant 7.867 with paired ' $t$ ' test $(\mathrm{t}=25.499)$

- The result of study shows that a structured teaching programme helps in increasing the knowledge and improving the practice of middle age adults regarding life style modification to prevent hypertension.

\section{Limitation}

Sample was only from the one village. This restrict the generality of the results

\section{Acknowledgement}

First of all, I thank God almighty for his grace and abundant blessings. He has showered on me throughout the course of study. His felt presence gave me the strength to successful completion this study.

I owe my special thanks to all the Participants who enthusiastically participated in the study and without whose co - operation the whole study would not have been possible. Thanks a lot for this work.

My heartfelt and sincere gratitude to all my friends for their constant encouragement and support during the study. I Especially heartfelt thanks to Gagandeep Kaur for giving me valuable suggestion and supports.

\section{References}

[1] Suddarth \& Brunner "A textbook of medical surgical nursing" $12^{\text {th }}$ Edition Year 2010 volume - 1, published by wolters kluwer (India) Pvt Ltd.890 - - 91.

[2] Misra Kritika, "A textbook of fundamental of Nursing", $1^{\text {st }}$ Edition year 2017, Volume - 2 published by Lotus Publishers, 736 - 37.

[3] Basavanthapa BT "A textbook of Medical Surgical Nursing" $2^{\text {nd }}$ Edition, Jaypee brother Medical Publisher (p) Ltd., 575 - 77.

[4] Javed Ansari Devender Kumar "Textbook of Medical surgical nursing" 2th Edition year 2015, Volume - $1^{\text {st }}$, Pee Vee Medical Publisher (P) Ltd., 825 - 26.

[5] IOSR Journal of nursing and health science (IOSR JNHS) Knowledge and perception related to hypertension life style modification and challenge that facing hypertension patient: 2015; 4 (6): 15 - 26.

[6] Park K, "Parks Textbook of Preventive and Social Medicine", $21^{\text {st }}$ Edition year 2013, M/s Banarsidas Bhanot publishers, 344 - 46.

[7] Wolter Kluwer /Lippincott Willians and Wilkins "A Textbook of Lippincott 's manual of nursing practice $8^{\text {th }}$ Edition year 2008 volume - 1, Published by Jaypee brother medical (p) Ltd, 466 - 67.

[8] Fadwa Alhalaiqal; a descriptive study of adherence to lifestyle modification factors among hypertensive patients (2017) 47: 273 - 281 Avalable from DOI: http: //dx. doi. org/10.18203/2394 - 6040. ijcmph20182151

[9] Olive Njambi,; Asbel Tanui Lifestyle modification in prevention of hypertension: Patient empowerment 2015; 2 (43): $213-16$
[10] Puveearasan Kongarasan Pankaj B. Shah; Knowledge and perception of hypertension among hypertensive patients attending rural health and training center, department of community medicine SRMC7\&RI.2018 department of community medicine, SRMC \& 2018 Jun; 5 (6): 2323 - 2326. file: $/ / / \mathrm{C}$ : /Users/hp/Downloads/2619 - 11656 - 2 - PB\%20 (1). pdf

[11]Dhakal M.; (2017) conducted a study which hospital based cross sectional study to evaluate awareness of lifestyle intervention among hypertension patient in Sikkam.2017 5 (4) Available from http: //medresearch. in/index. php /IJMRR/article/view/1618/2592 